\title{
29. PALEOMAGNETISM OF SEDIMENTS, LEG 37
}

\author{
James M. Hall and Patrick J.C. Ryall, ${ }^{1}$ \\ Department of Geology, Dalhousie University, Halifax, Nova Scotia, Canada
}

\begin{abstract}
A study of 94 semioriented sediment samples from DSDP Sites $332,333,334$, and 335 is described. Of these samples 91 were obtained from sediment above the first basalt layer of oceanic basement and 3 from sediment intercalated among the basement basalts. Sediment NRM intensity varies widely from $3 \times 10^{-8}$ to $2 \times 10^{-4}$ $\mathrm{emu} / \mathrm{cm}^{3}$. Reliable stable inclinations, obtained by alternating-field cleaning of NRMs, were generally evident only where NRM intensity exceeded $1 \times 10^{-6} \mathrm{emu} / \mathrm{cm}^{3}$. Stable NRM inclinations show that many geomagnetic polarity epochs are represented in the sediment columns. Average sediment stable NRM inclinations are closer to ideal dipole inclinations of $\pm 56^{\circ}$ than are stable NRM inclinations for the underlying basalts. However, site average values are generally a little shallow, even when corrected for the effect of a northwards offset geomagnetic source dipole. It is thought that differences between measured and expected inclinations are the result of the inclusion of transition inclinations, together with a degree of tectonic rotation of the sediment section at Site 333, rather than absolute plate motion.
\end{abstract}

\section{INTRODUCTION}

The paleomagnetic study of the sediments lying above oceanic volcanic basement has several aims. The sediments carry a magnetic record of value in its own right, which incorporates parts of the history of geomagnetic reversals and, in principle, information that may be used to determine absolute plate motion. In addition, comparison of the paleomagnetic record of the sediments and the underlying basalts may help to understand the many anomalous NRM inclinations recorded by the basalts (Hall and Ryall, this volume).

\section{SAMPLING AND MEASUREMENT}

Ninety-four samples were taken from the working half of the main core in the manner used during DSDP Leg 34 (Ade-Hall and Johnson, 1976). Of these, 91 were from sediment lying above the uppermost basement basalts and 3 were from sediments intercalated within the basalts. Sample volumes average $6.7 \mathrm{~cm}^{3}$, with average mass close to $10 \mathrm{~g}$. A large recovery of basalt precluded the shipboard measurement of sediment samples. The NRM of the latter were measured at Dalhousie University using a Schonstedt DSM 1 digital spinner magnetometer. Where justified, alternatingfield partial demagnetization was carried out to isolate stable NRM inclinations.

\footnotetext{
'Now at School of Physics, Universiti Sains Malaysia, Minden, Pulau Pinang, Malaysia.
}

\section{RESULTS}

A wide range of NRM intensities was encountered, spanning the interval from $3.3 \times 10^{-8} \mathrm{emu} / \mathrm{cm}^{3}$ to 2.09 $\times 10^{-4} \mathrm{emu} / \mathrm{cm}^{3}$ (Table 1). Reliable paleomagnetic information could not be obtained for 27 of the 35 samples with intensities of less than $1 \times 10^{-6} \mathrm{emu} / \mathrm{cm}^{3}$. This was partly due to sample magnetic moment approaching specimen holder magnetic moment. While the computer associated with the magnetometer can be programmed to remove the sample holder moment from the measured moment, variations of the sample holder moment with time do not allow confidence in this operation. In addition, relatively low moments are sometimes associated with low magnetic stability, suggesting that strong and weak samples may contain different types as well as amounts of magnetic phases.

Alternating field demagnetization indicated that a wide range of NRM stabilities occurs. Of 57 samples that yielded satisfactory stable NRM inclinations, 41 $(72 \%)$ showed a difference between NRM and stable inclination of more than $5^{\circ}$. The widespread occurrence of large soft components supports the need for systematic remanence cleaning of sediment NRMs. Stable directions were usually but not always closer to the ideal dipole inclinations $\left( \pm 56^{\circ}\right)$ for the sites than were NRM inclinations.

The distribution of satisfactory stable NRM inclinations reflects the distribution of NRM intensities (Tables 1, 2, Figure 1). Thus Holes 332A and 333, with $60 \%$ and $70 \%$ of samples, respectively, with NRM values of less than $1 \times 10^{-6} \mathrm{emu} / \mathrm{cm}^{3}$, yielded few stable inclinations. Sites 334 and 335, on the other hand, gave 
TABLE 1

Paleomagnetic Properties of Sediments at Leg 37 Sites

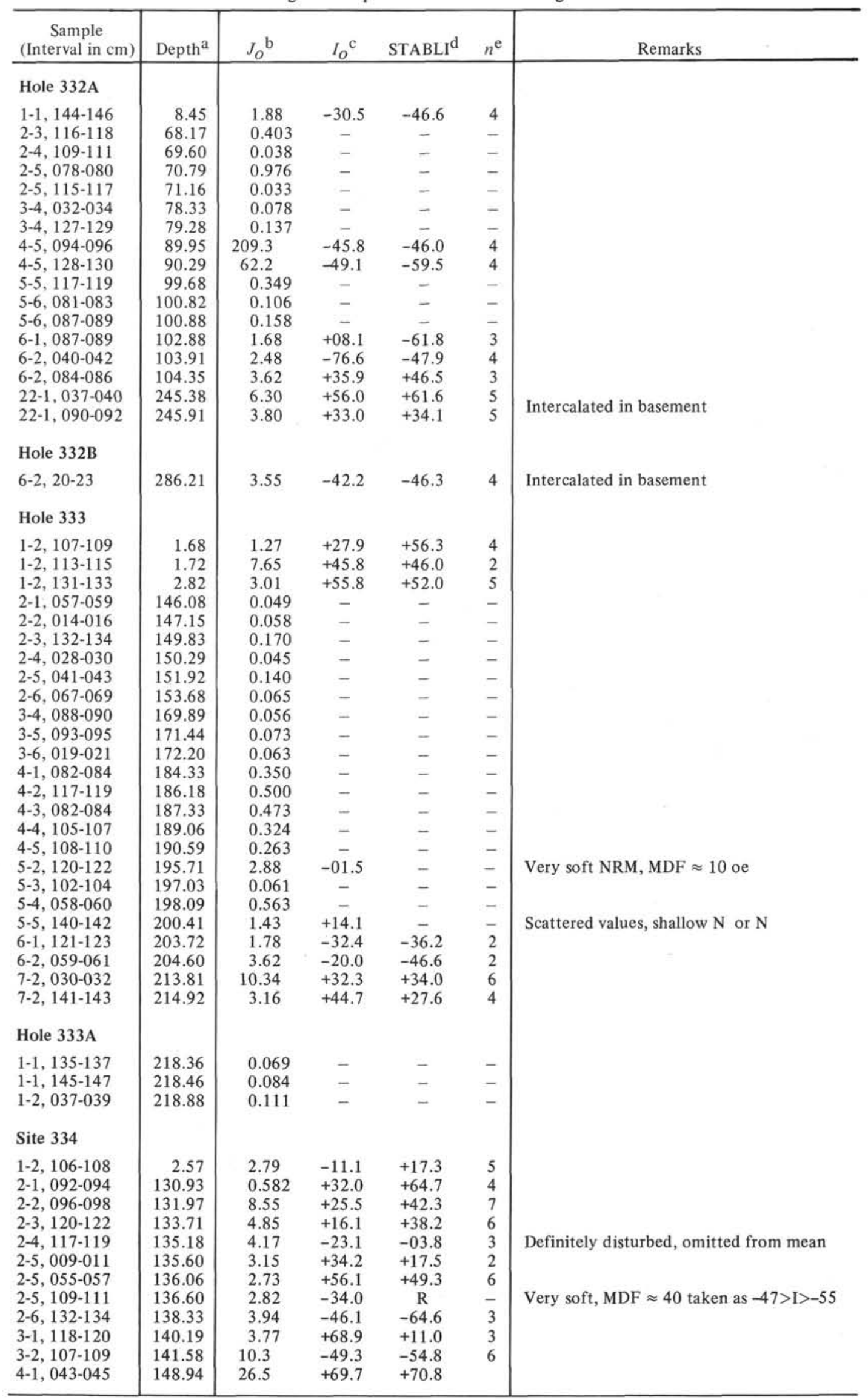


TABLE 1 - Continued

\begin{tabular}{|c|c|c|c|c|c|c|}
\hline $\begin{array}{c}\text { Sample } \\
\text { (Interval in } \mathrm{cm} \text { ) }\end{array}$ & Depth ${ }^{\mathrm{a}}$ & $J_{o}^{\mathrm{b}}$ & $I_{O}^{\mathrm{c}}$ & STABLI $^{\mathrm{d}}$ & $n^{\mathrm{e}}$ & Remarks \\
\hline $5-3,083-085$ & 161.84 & 7.31 & +60.0 & +67.6 & 3 & \\
\hline $5-4,076-078$ & 163.27 & 27.0 & +38.9 & +49.4 & 5 & \\
\hline $5-4,137-139$ & 163.88 & 8.23 & +27.9 & +46.0 & 5 & \\
\hline $6-1,034-036$ & 167.85 & 28.1 & +52.5 & +47.8 & 3 & \\
\hline $6-2,056-058$ & 169.57 & 14.3 & +37.4 & +36.1 & 5 & \\
\hline $7-1,132-134$ & 178.33 & 7.14 & +28.2 & +37.0 & 5 & \\
\hline $7-2,137-140$ & 179.88 & 5.19 & +56.7 & +43.3 & 4 & \\
\hline $7-3,146-148$ & 181.47 & 2.99 & +48.1 & +54.2 & 5 & \\
\hline $7-4,060-062$ & 182.11 & 10.8 & +31.4 & +45.3 & 4 & \\
\hline $7-5,057-059$ & 183.58 & 17.4 & +37.4 & +49.2 & 4 & \\
\hline $7-6,143-145$ & 185.94 & 25.4 & +48.2 & +67.8 & 2 & \\
\hline $8-2,106-108$ & 189.07 & 8.34 & -59.0 & -67.1 & 5 & \\
\hline $9-2,107-109$ & 197.08 & 2.66 & -16.2 & -24.3 & 2 & \\
\hline $9-3,085-087$ & 198.36 & 1.60 & +19.7 & -75.4 & 3 & \\
\hline $9-4,099-101$ & 200.00 & 1.90 & -44.1 & -09.8 & 4 & \\
\hline $10-3,135-137$ & 209.56 & 2.42 & +30.5 & +19.4 & 2 & \\
\hline $10-4,121-123$ & 211.22 & 1.60 & -34.6 & -41.9 & 4 & \\
\hline $11-2,124-126$ & 217.75 & 9.30 & -24.9 & -21.8 & 7 & \\
\hline $11-3,054-056$ & 218.57 & 1.38 & -45.4 & -54.9 & 9 & \\
\hline $11-4,128-130$ & 220.89 & 5.16 & +65.0 & +64.9 & 6 & \\
\hline $12-4,085-07$ & 229.86 & 5.21 & +58.5 & +63.6 & 5 & \\
\hline $13-4,089-091$ & 219.90 & 2.68 & +68.0 & +79.2 & 2 & \\
\hline $13-5,107-109$ & 214.08 & 3.01 & +60.1 & - & - & Very soft, $\mathrm{MDF} \approx 65$, probably $\mathrm{N}$ \\
\hline $13-6,139-141$ & 242.90 & 0.720 & +49.3 & - & - & $\mathrm{N}$ \\
\hline $13-6,145-147$ & 242.96 & 2.81 & -34.9 & -58.5 & 3 & \\
\hline $14-1,134-136$ & 244.85 & 6.95 & -37.8 & - & - & Very soft, $\mathrm{MDF} \approx 30$ \\
\hline \multicolumn{7}{|l|}{ Site 335} \\
\hline $1-3,047-049$ & 90.48 & 1.90 & +43.8 & - & - & Shallow $\mathrm{R}$ or $\mathrm{R}$ \\
\hline $1-4,070-072$ & 92.21 & 0.103 & -57.4 & -64.3 & 3 & Very stable, MDF $>200$ \\
\hline $2-2,056-058$ & 127.07 & 0.189 & - & - & - & \\
\hline $2-5,137-139$ & 132.38 & 0.994 & +03.1 & - & - & Shallow $\mathrm{R}$ or $\mathrm{R}$ \\
\hline $3-1,054-056$ & 220.55 & 3.39 & +72.0 & +74.3 & 3 & \\
\hline $3-1,121-123$ & 221.22 & 1.92 & -49.5 & -46.7 & 4 & \\
\hline $4-2,123-25$ & 317.74 & 0.174 & -41.6 & -52.9 & 2 & \\
\hline $4-3,111-113$ & 319.12 & 38.2 & -62.6 & -54.4 & 5 & \\
\hline $5-1,080-082$ & 448.83 & 10.9 & +42.0 & +41.3 & 6 & \\
\hline $5-1,094-096$ & 448.95 & 10.4 & +34.2 & +33.8 & 2 & \\
\hline
\end{tabular}

\footnotetext{
${ }^{\mathrm{a} D e p t h}$ subbottom.

${ }^{b}$ NRM intensity before demagnetization $\times 10^{6} \mathrm{emu} / \mathrm{cm}^{3}$.

${ }^{\mathrm{c}} \mathrm{NRM}$ inclination before demagnetization $\left({ }^{\circ}\right)$.

${ }^{d}$ Inclination of stable remanence $\left(^{\circ}\right)$.

$\mathrm{e}_{\text {Number of values contributing to STABLI. }}$
}

stable inclinations for almost every sample, including all but one of the few samples with NRM of less than 1 $\times 10^{-6} \mathrm{emu} / \mathrm{cm}^{3}$.

At all sites the profiles of stable NRM with depth show that a number of geomagnetic reversals are recorded in the sediment column (Figure 2). This is to be expected for the young Neogene, when field reversal was a frequent occurrence (Heirtzler et al., 1968). While the episodic nature of basalt eruption (Hall and Ryall, this volume) provides only a fragmentary record of the geomagnetic field, the sediments, which are continuously deposited nanno-foram oozes, probably contain a more complete record of the geomagnetic field.

We have attempted to match the polarity sequences of the sediment sections with the time-geomagnetic polarity zones of Talwani et al. (1971), modified after Blakely (1974) for $t>7.3 \mathrm{~m} . \mathrm{y}$. The matching of observed and standard profiles is valuable in confirming the sediment ages now rather broadly confined by paleontological work, and in recognizing the changes in sedimentation rate at each site. Presently the density of the paleomagnetic data alone is everywhere insufficient for a unique match with standard profiles. The sediment record at Site 334, where coring was continuous from 130 meters subbottom to basement at 259 meters subbottom, with reliable stable inclinations available for almost every sample, is most promising for a match.

A combination of paleomagnetic polarity and paleontological data has been used by Howe and Miles (this volume) to estimate the age of the Site 334 sediment section. Their best estimate for the age of the basal sediment at this site is $11.6 \mathrm{~m} . y$. , which conflicts with the apparent location of the site within crust of anomaly 5 (8.9 to 10.0 m.y.) age. According to the paleontological-paleomagnetic match anomaly 5 time at this site is represented by the sediments of Cores 4 to 7 inclusive, at 148.5 to 186.5 meters subbottom (Figure 2 ), rather than the basement basalts at 260 meters subbottom. Regardless of the difficulty in matching ages at 
TABLE 2

Site-Average Sediment Paleomagnetic Properties and Selected Site-Average Basalt Properties for Comparison

\begin{tabular}{|c|c|c|c|c|c|}
\hline Site/Hole & $\begin{array}{l}\text { NRM Intensity } \\
\left(\times 10^{6} \mathrm{emu} / \mathrm{cm}^{3}\right) \\
\text { Arithmetic Av. }\end{array}$ & Logarithm ${ }^{\mathrm{c}} \mathrm{Av}$. & $\begin{array}{l}\text { Sediment Av. Stable } \\
\text { NRM inclination } \\
\text { (Basalt Value) }\left({ }^{\circ}\right)\end{array}$ & $\begin{array}{l}\text { Apparent Paleo- } \\
\text { latitude }\left({ }^{\circ} \mathrm{N}\right) \\
\text { (Basalt Value) }\end{array}$ & $\begin{array}{c}\text { Apparent Paleolatitude } \\
\text { Corrected for Offset } \\
\text { Dipole (Basalt Value) }\left({ }^{\circ} \mathrm{N}\right)\end{array}$ \\
\hline $332 \mathrm{~A}$ & $20.0 \pm 147^{\mathrm{a}}$ & $0.74 \pm 3.29^{\mathrm{a}}$ & $\begin{array}{r}56.2 \pm 5.0^{\mathrm{a}} \\
(37.7 \pm 6.0)\end{array}$ & $\begin{array}{c}36.8 \pm 5.3 \\
(21.1 \pm 4.4)\end{array}$ & $\begin{array}{c}41.1 \pm 5.8 \\
(24.0 \pm 4.7)\end{array}$ \\
\hline $332 \mathrm{~B}$ & - & - & $(27.5 \pm 3.7)$ & $(14.6 \pm 2.3)$ & $(17.0 \pm 2.3)$ \\
\hline $\begin{array}{l}333 \\
333 \mathrm{~A}\end{array}$ & $1.38 \pm 0.46$ & $0.35 \pm 1.06$ & $\begin{array}{c}42.7 \pm 3.9 \\
(15.5 \pm 3.0)\end{array}$ & $\begin{array}{c}24.8 \pm 3.0 \\
(7.9 \pm 1.6)\end{array}$ & $\begin{array}{c}27.9 \pm 2.7 \\
(10.0 \pm 1.6)\end{array}$ \\
\hline 334 & $7.46 \pm 3 / 24$ & $4.83 \pm 0.42$ & $\begin{array}{c}45.8 \pm 3.5 \\
(53.1 \pm 3.1)\end{array}$ & $\begin{array}{c}27.2 \pm 2.5 \\
(33.7 \pm 3.0)\end{array}$ & $\begin{array}{c}30.6 \pm 3.0 \\
(37.7 \pm 3.2)\end{array}$ \\
\hline 335 & $6.82 \pm 3.71$ & $1.68 \pm 2.28$ & $\begin{array}{c}46.4 \pm 7.6 \\
(-63.5 \pm 1.1)\end{array}$ & $\begin{array}{c}27.8 \pm 7.1 \\
(45.1 \pm 1.4)\end{array}$ & $\begin{array}{c}31.1 \pm 7.0 \\
(50.4 \pm 1.5)\end{array}$ \\
\hline All sites & $7.32 \pm 2.37^{b}$ & $1.46 \pm 0.74^{b}$ & $\begin{aligned} 47.8 & \pm 2.9^{c} \\
(39.5 & \pm 8.6)\end{aligned}$ & $\begin{aligned} 29.2 & \pm 2.6^{c} \\
(24.5 & \pm 6.7)\end{aligned}$ & $\begin{array}{c}32.7 \pm 2.9^{6} \\
(27.8 \pm 7.3)\end{array}$ \\
\hline
\end{tabular}

Note: Present Latitude of Sites: $36^{\circ} \mathrm{N}$ to $37^{\circ} \mathrm{N}$ - Ideal Dipole Inclination: \pm 56 to $57^{\circ}$

${ }^{a}$ RMS scatter about average value.

${ }^{b}$ Average for all samples giving unit weight to each sample.

${ }^{c}$ Average for all sites giving unit weight to each site.

this site the high quality of the sediment paleomagnetic data would make it worthwhile to core completely the sediment section when the site is reoccupied to extend penetration of the basement mélange.

Sediment stable NRM inclinations bear on two further problems, the questions of absolute plate motion and the explanation of the many shallow basement stable NRMs at Sites 332 and 333.
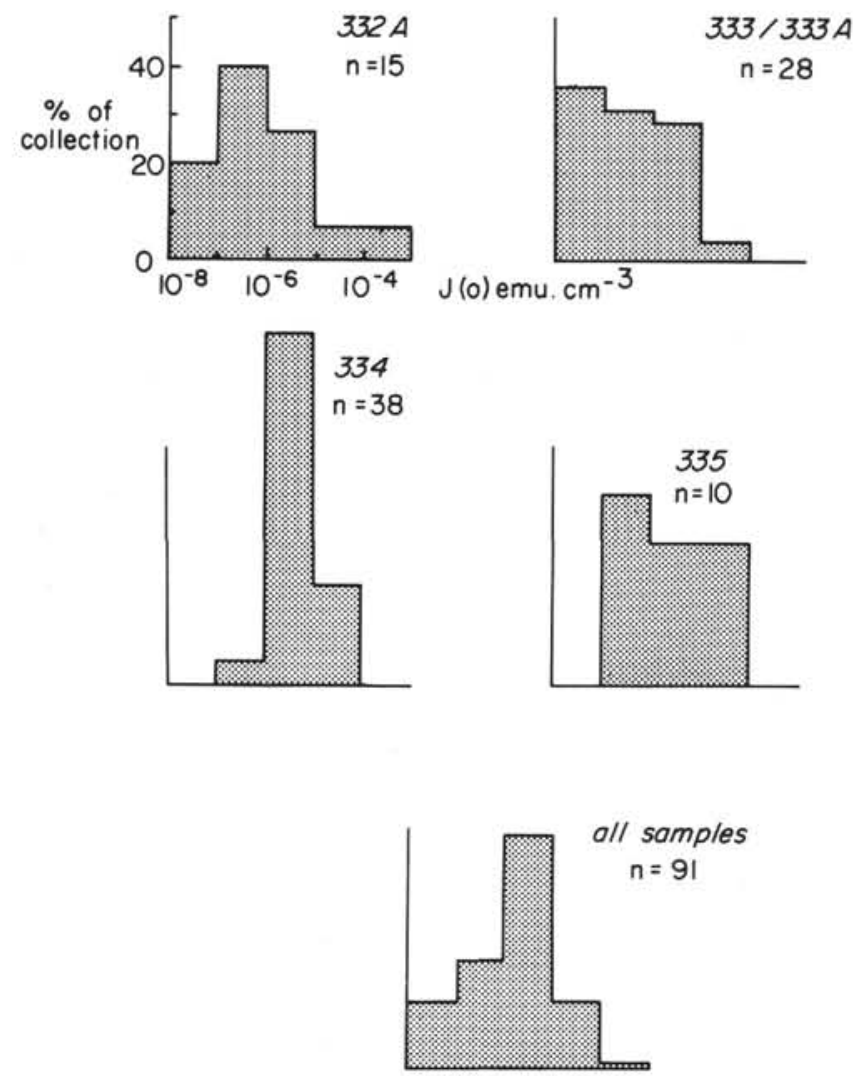

Figure 1. Histograms showing distributions of sediment NRM intensities by site and for the collection as a whole.
With average sedimentation rates ranging from 2.9 $\mathrm{cm} / 1000 \mathrm{yr}$ to $6.2 \mathrm{~cm} / 1000 \mathrm{yr}$, the $2-\mathrm{cm}$ diameter sediment samples each represent on the average paleomagnetic inclinations for from $300 \mathrm{yr}$ to $700 \mathrm{yr}$. These time intervals comprise at least large fractions of the duration of observed secular variation quasicycles. For this reason the sediment paleomagnetic data will give a very much better representation of the average paleomagnetic field than will the underlying basalts, and with this, a much improved opportunity to obtain a reliable estimate of absolute plate motion. The more representative nature of the sediment stable NRM inclinations is evident in Figure 3, where inclinations are clustered about the ideal dipole inclination, in contrast with the basalt values (Table 2, and Hall and Ryall, this volume). However, the distributions of Figure 3 are generally not simple, with several peaks and tails to low values. The complicated form of the distributions raises the question of which part of the data represents a largely axial dipole field, and should be averaged to obtain absolute plate motion. The shallow values, some of which probably mark transitions of the geomagnetic field, and therefore should be excluded from averages, cannot be excluded from the data of the distributions on present knowledge. This follows since Wilson et al. (1972) have shown that the stable dipole states of geomagnetic field can include some shallow directions. Table 2 gives values of apparent absolute plate motion for all the sites. We note that a simple treatment of the sediment paleomagnetic data gives paleolatitudes that are closer to the present site latitudes than do the underlying basalts, but which are, on the average, still displaced by a large angle for the small times involved. Thus, the average sediment-based site paleolatitude is $29.2 \pm 2.6^{\circ} \mathrm{N}$ against an average present site latitude of $36.5^{\circ} \mathrm{N}$. If this difference is interpreted in terms of plate motion, $810 \mathrm{~km}$ northwards motion over $\sim 5 \mathrm{~m}$.y., at an average rate of $17 \mathrm{~cm} / \mathrm{yr}$ is implied. This is probably unrealistically high. Wilson $(1970,1971)$ has shown that during the Neogene the geomagnetic dipole has been offset from the earth's center towards the North Pole 

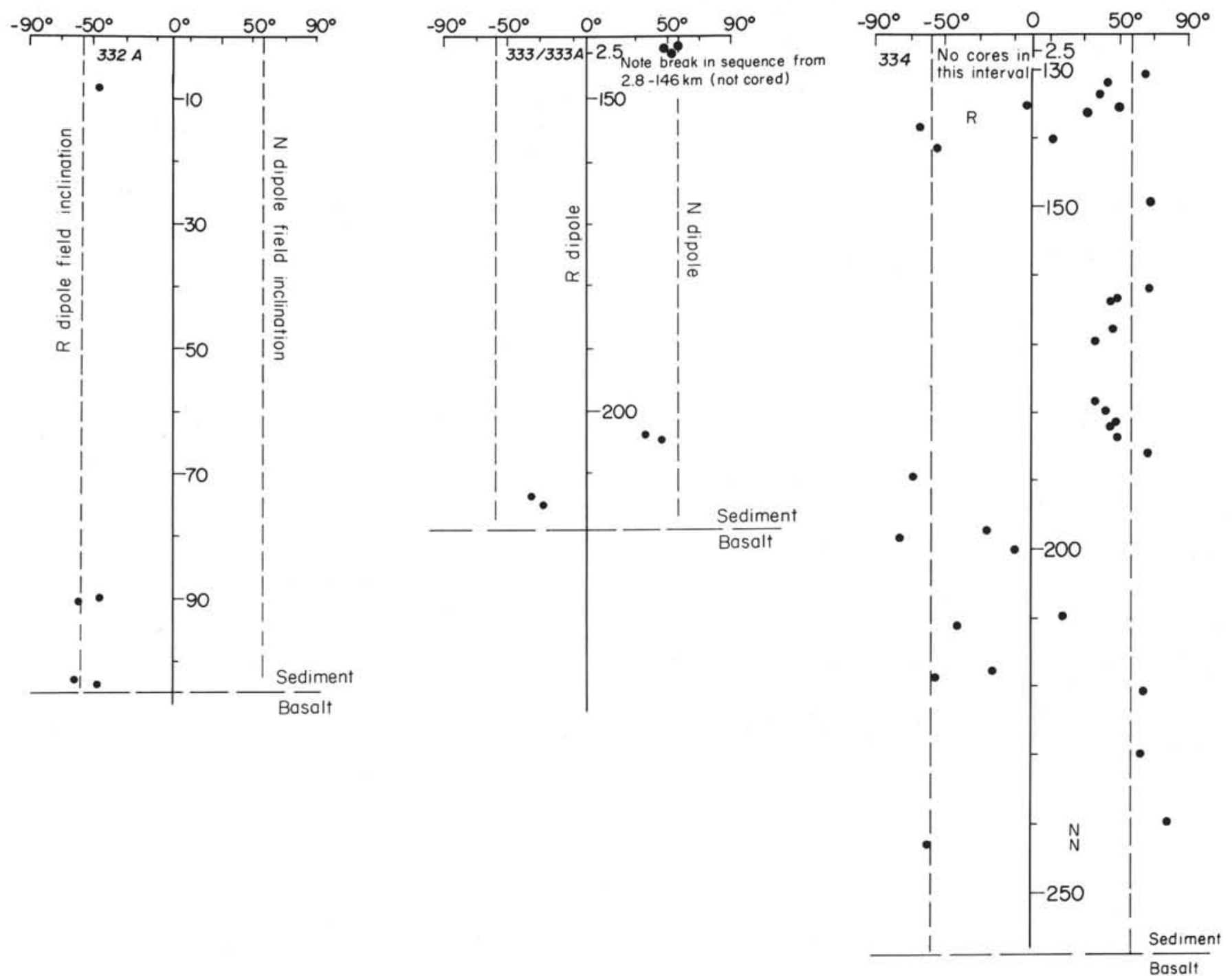

Figure 2. Distribution with depth of stable sediment NRM inclinations. Site 335 data are not shown as the few cores are very widely spaced.

by $285 \mathrm{~km}$ on the time average. The effect of this offset at the latitude of the Leg 37 sites is that dipole inclinations will average close to $4^{\circ}$ shallower than for a corresponding centered axial dipole source. Since our paleomagnetic data are biased in this sense it seems sensible to correct the apparent plate motion for an offset dipole effect. We see from the right-hand column of Table 2 that correction for an offset dipole brings the sediment (and basalt) paleolatitudes closer but not exactly to the present site latitudes. Average apparent absolute plate motion for the sediments is now reduced to $4^{\circ}$ of latitude in $\sim 5$ m.y., or an average northwards velocity of 9 $\mathrm{cm} / \mathrm{yr}$. This figure is still high and unremoved bias from two sources may be expected. One is the presence of a number of geomagnetic transition inclinations, which should be removed from the average inclinations for the reason described above. The other is the possibility that tectonic rotation of one or more sediment columns has biased inclinations away from dipole and towards shallow values. The situation at Site 333 is particularly intriguing in this respect. Here the topmost sediments are magnetized with dipole inclinations. However, four samples from close to the base of the sediment section ( 2 of $\mathrm{N}$ polarity and 2 of $\mathrm{R}$ polarity) all have rather shallow inclinations. This would be consistent with a rotation of at least the lowermost 20 meters of sediments by $20^{\circ}$ about an east-west axis, the dip now being towards the south.

While this is not a unique interpretation of the shallow sediment NRM inclinations, it would fit conveniently in a model of basement rotation in the same sense of some $40^{\circ}$, which would be responsible for the typically shallow basement stable NRM inclinations at this site. If both sediment and basement shallow inclinations are the result of tectonic rotation it is implied that $20^{\circ}$ of rotation occurred before sedimentation started and the remaining $20^{\circ}$ while sedimentation was in progress, with rotation terminating before the topmost sediments were deposited. This model, if correct, provides a unique means of following the tectonic history of a basement segment to the present day. It would be desirable to extend sampl- 


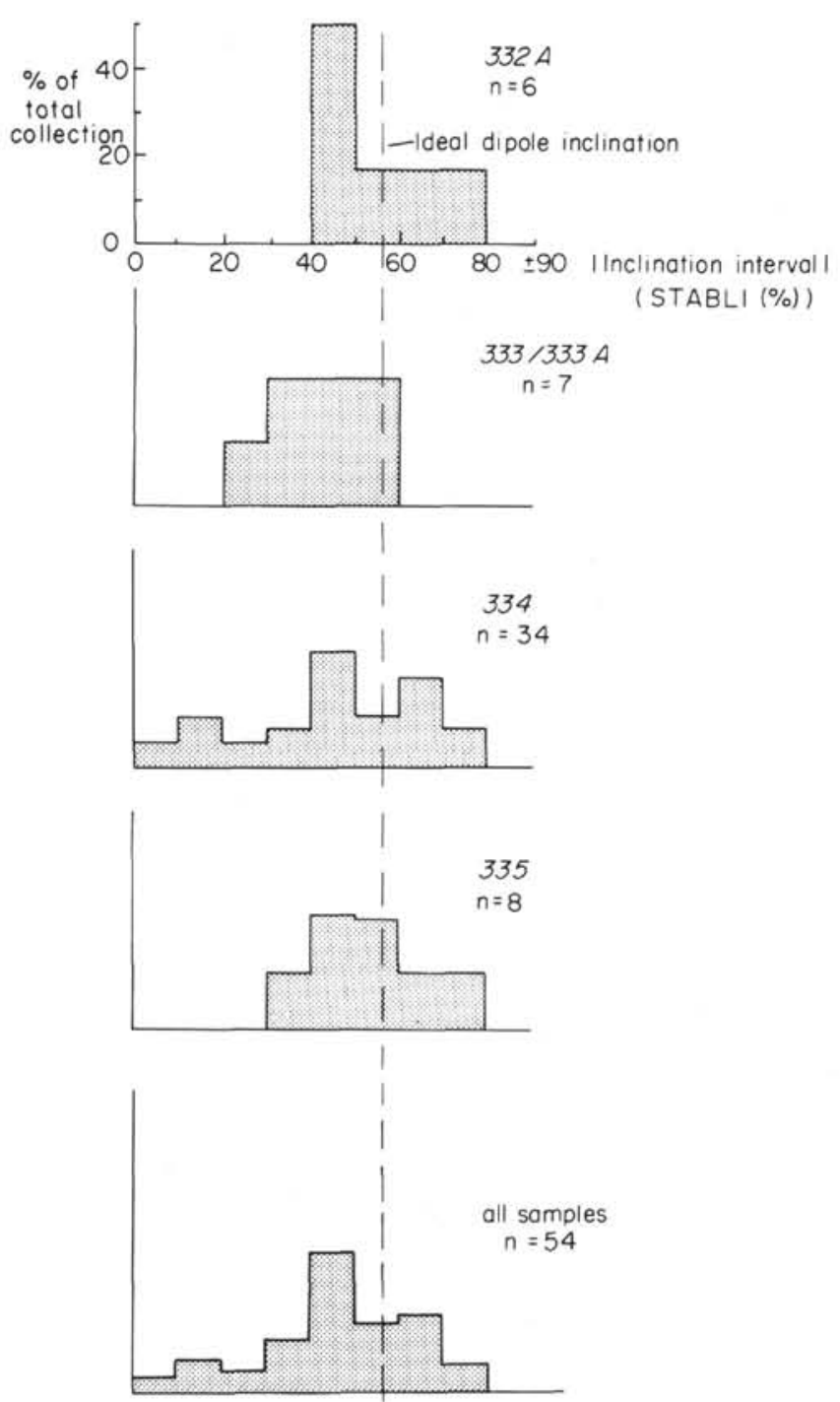

Figure 3. Histograms showing distributions of sediment stable NRM inclinations by site and for the collection as $a$ whole. The dashed line represents the inclination at the latitude of the sites for a centered axial dipole geomagnetic field source.

ing of the Site 333 sediment section but this is presently impossible in view of the disturbed nature of the unsampled parts of the core.

\section{SUMMARY AND CONCLUSIONS}

The main results of the Leg 37 sediment paleomagnetism study are in the record of time-geomagnetic polarity zoning, the better agreement of sediment stable NRM inclinations than basalt inclinations with ideal dipole field inclinations, and the hint of evidence for tectonic rotation of both sediment and basement sequences at Site 333. The results obtained so far are sufficiently interesting to encourage further sampling of the Leg 37 sediment sections during an IPOD leg.

\section{ACKNOWLEDGMENTS}

We should like to acknowledge John Dewar, Jeff Clark, Tim Milligan, and Lata Hall for help with the shipboard sampling and shore-based measurements. Monika Michaelis and Ruth Feldbauer kindly typed the manuscript, which was read critically by Paul Johnson.

\section{REFERENCES}

Ade-Hall, J.M. and Johnson, H.P., 1976. Paleomagnetism of sediments, Leg 34. In Hart, S.R., and Yeats, R.S., et al., Initial Reports of the Deep Sea Drilling Project, Volume 34: Washington (U.S. Government Printing Office), p. $533-539$

Blakely, R.J., 1974. Geomagnetic reversals and crustal spreading rates during the Miocene: J. Geophys. Res., v. 79 , p. $2979-2985$.

Heirtzler, J.R., Dickson, G.O., Herron, E.M., Pitman, W.C., and Le Pichon, X., 1968. Marine magnetic anomalies, geomagnetic field reversals, and motions of the ocean floors and continents: J. Geophys. Res., v. 73, p. 21192136.

Talwani, M., Windisch, C.C., and Langseth, M.G., 1971. Reykjanes Ridge Crest: A detailed geophysical survey: J. Geophys. Res., v. 76, p. 473-517.

Wilson, R.L., 1970. Permanent aspects of the Earth's nondipole magnetic field over upper Tertiary times: Geophys. J., v. 19 , p. $417-437$.

1971. Dipole offset-the time average paleomagnetic field over the past 25 million years: Geophys. J., v. 22, p. 491-504.

Wilson, R.L., Dagley, P., and McCormack, A.G., 1972. Paleomagnetic evidence about the source of the geomagnetic field: Geophys. J., v. 28, p. 285-294. 